\title{
Disclosure of New Type 2 Diabetes Diagnoses to Younger Adults: a Qualitative Study
}

\author{
Anjali Gopalan, $M D, M S^{\top} \oplus$, Maruta A. Blatchins, $B A^{\top}$, Andrea Altschuler, $P h D^{7}$, \\ Pranita Mishra' , Issa Fakhouri, $\mathrm{MD}^{2}$, and Richard W. Grant, MD, $\mathrm{MPH}^{7}$ \\ ${ }^{7}$ Kaiser Permanente Northern California Division of Research, Oakland, CA, USA; ${ }^{2}$ Kaiser Permanente Northern California Stockton Medical Offices, \\ Stockton, CA, USA.
}

BACKGROUND: Adults diagnosed with type 2 diabetes at a younger age are at increased risk for poor outcomes. Yet, little is known about the early experiences of these individuals, starting with communication of the diagnosis. Addressing this knowledge gap is important as this initial interaction may shape subsequent disease-related perceptions and self-management.

OBJECTIVE: We examined diagnosis disclosure experiences and initial reactions among younger adults with newly diagnosed type 2 diabetes.

PARTICIPANTS: Purposive sample of adult members of Kaiser Permanente Northern California, an integrated healthcare delivery system, diagnosed with type 2 diabetes before age 45 years.

APPROACH: We conducted six focus groups between November 2017 and May 2018. Transcribed audio recordings were coded by two coders using thematic analysis.

KEY RESULTS: Participants ( $n=41)$ were 38.4 ( \pm 5.8 ) years of age; 10 self-identified as Latinx, 12 as Black, 12 as White, and 7 as multiple or other races. We identified variation in diagnosis disclosure experiences, centered on four key domains: (1) participants' sense of preparedness for diagnosis (ranging from expectant to surprised); (2) disclosure setting (including in-person, via phone, via secure message, or via review of results online); (3) perceived provider tone (from nonchalant, to overly fear-centered, to supportive); and (4) participants' emotional reactions to receiving the diagnosis (including acceptance, denial, guilt, and/or fear, rooted in personal and family experience).

CONCLUSIONS: For younger adults, the experience of receiving a diabetes diagnosis varies greatly. Given the long-term consequences of inadequately managed diabetes and the need for early disease control, effective initial disclosure represents an opportunity to optimize initial care. Our results suggest several opportunities to improve the type 2 diabetes disclosure experience: (1) providing pre-test counseling, (2) identifying patient-preferred settings for receiving the news, and (3) developing initial care strategies that acknowledge and address the emotional distress triggered by this life-altering, chronic disease diagnosis.

Received June 1, 2020

Accepted December 15, 2020

Published online January 26, 2021
KEY WORDS: type 2 diabetes; diagnosis; patient-provider communication.

J Gen Intern Med 36(6):1622-8

DOI: $10.1007 / \mathrm{s} 11606-020-06481-y$

(C) Society of General Internal Medicine 2021

\section{INTRODUCTION}

Approximately $30 \%$ of the 1.5 million US adults diagnosed with diabetes each year are under age 45 years at the time of diagnosis. ${ }^{1}$ These younger individuals have a particularly poor prognosis, presenting with more severe hyperglycemia, with greater obesity, and with a higher risk for diabetes-related micro- and macrovascular complications. ${ }^{1-9}$ Receiving a diabetes diagnosis at this younger age may be especially daunting. Possible unique challenges include needing to accept a chronic disease diagnosis that is typically associated with middle or older ages, starting a daily medication, and committing time (often during work hours) to medical visits. ${ }^{9-11}$ The importance of overcoming immediate challenges cannot be understated, as studies have shown that achieving glycemic control and recommended weight loss goals during the year following diagnosis reduces the long-term risk of diabetesrelated complications. ${ }^{12-14}$

Despite the gravity of type 2 diabetes onset at a younger age, and the clinical importance of the early post-diagnosis period, little is known about how patients experience the initial diagnosis disclosure. Evidence suggests that the disclosure conversation shapes patients' diabetes-related experiences, with individuals valuing clarity and timeliness, and disclosures described as supportive and encouraging associated with lower levels of diabetes distress and greater engagement with selfmanagement. ${ }^{15-18}$ Providers also recognize the importance of this initial conversation and its impact on individuals' subsequent self-care. ${ }^{19}$ Yet, in contrast to other serious, life-altering diagnoses, e.g., HIV or cancer, little attention has been paid to establishing comparable best practices for type 2 diabetes. ${ }^{20,21}$

We conducted focus groups with adults with younger-onset type 2 diabetes to learn about how they received and reacted to this diagnosis. This qualitative study may inform type 2 diabetes diagnosis disclosure approaches tailored to this population's unique needs and experiences. 


\section{METHODS}

\section{Design and Study Setting}

We conducted six focus groups composed of adults with younger-onset type 2 diabetes ( $<45$ years at diagnosis). Focus groups were chosen over interviews to capture a greater range of perspectives and to enrich the collected data via participant interactions. ${ }^{22,23}$ Six groups were planned a priori based on prior methodological research, with the option to conduct more, if needed. ${ }^{24}$ Participants were members of Kaiser Permanente Northern California (KPNC), a large integrated healthcare delivery system. The study was approved by the KPNC Institutional Review Board. Participants provided written informed consent and received a $\$ 40$ Target gift card after each meeting.

\section{Participants}

Using electronic health record (EHR) data, we purposively identified a potentially eligible sample of Latinx, Black, and White adults from two geographic areas (one predominantly urban and one more rural) who were 21-44 years old at the time of diagnosis and were diagnosed within the prior 2 years. This age cutoff reflects the American Diabetes Association's recommendation to begin routine diabetes screening at age 45 years. We excluded non-English proficient individuals, as well as individuals who had gestational or type 1 diabetes (identified via validated algorithms). ${ }^{25,26}$

After obtaining primary care provider (PCP) approval, we mailed eligible individuals a letter describing the study and provided an opportunity to opt out of participation. Individuals who did not opt out were contacted by phone. Call order was determined by date of type 2 diabetes diagnosis, starting with individuals diagnosed most recently.

Interested individuals were assigned to one of six focus groups based on their EHR-reported race/ethnicity and geographic area, with a goal of 6-8 participants per group. This group assignment strategy was chosen to acknowledge the role that race/ethnicity and geography play in individuals' lives and their health-related experiences, given evidence that people with more shared experiences may be more open with one another. ${ }^{27,28}$

\section{Focus Group Procedures}

The focus groups were conducted between November 2017 and May 2018 and led by an experienced moderator (AA, female, PhD sociology, Practice Specialist at KPNC Division of Research) with whom participants had no prior relationship. $\mathrm{MAB}$, a research associate, and $\mathrm{AG}$, the principal investigator, were present and took field notes. Meetings were held in a conference room within a KPNC medical facility.

To start, the moderator discussed group etiquette (e.g., encourage interaction, listen respectfully without interrupting) and confidentiality. We used a narrative approach to prompt participants to share the story of how they were diagnosed.
This approach was intended to aid participants in recalling the events surrounding their diabetes diagnosis. ${ }^{29,30}$ All participants were given the opportunity to share their diagnosis story, but individuals were not compelled to share. The remainder of the focus group guide was not structured around personal narratives. The moderator followed the focus group guide but prompted further details or asked the group for thoughts, as appropriate. Each focus group met for two 60-90-min meetings, held 2 weeks apart, to enhance the depth and credibility of findings. ${ }^{31}$ The focus group guide questions were nearly all answered during the first meeting. Second meetings were used to answer any remaining questions and to revisit or expand on topics raised during the first meetings (prompted by the moderator or participants). No changes were made to the guide over time. Individuals who only attended the second meeting were still given the opportunity to share their diagnosis story. All participants completed a short questionnaire to collect demographic information not available from the EHR (e.g., educational attainment). Session audio recordings were transcribed verbatim by a professional service; participants did not review transcripts.

Team members who attended all the meetings (AA, MAB, AG) met regularly to review field notes and discuss preliminary themes. Following the final two meetings, all agreed that thematic saturation was achieved (no novel information heard), and additional groups were unnecessary.

The transcripts were analyzed deductively and inductively using a thematic analysis approach. ${ }^{32}$ Two independent coders (MAB, AG) read the transcripts twice. Codes identified within the data were systematically defined to create a codebook. Deductive codes were rooted in the research question regarding diagnosis disclosure experiences (e.g., when, where). Both reviewers coded each transcript and met regularly to compare coding. Any discrepancies were resolved through discussion leading to consensus. Codes were then organized into themes and subthemes. Finally, the research team selected relevant data elements (representative quotes) related to the themes and subthemes. NVivo Qualitative Analysis Software (QSR International Pty. Ltd, version 11, 2015) was used to support the analysis. Participants did not provide feedback on the coding or themes.

\section{RESULTS}

Of 514 identified individuals, 304 were contacted via phone regarding participation (210 not contacted due to PCP disapproval [5], missing address [2], sample already recruited [203]), of which 63 agreed to participate (others not interested/available [85], did not meet eligibility criteria [13], or were never reached [143]). Individuals who were not contacted because the sample was recruited $(n=203)$ did not differ by race/ethnicity from those who were contacted. A total of 41 individuals attended at least one focus group meeting (31 attended both) (Table 1). The groups were lively, interactive, 
Table 1 Focus Group Participant Characteristics

\begin{tabular}{|c|c|c|c|}
\hline & Overall & $\begin{array}{l}\text { Predominantly } \\
\text { urban }\end{array}$ & $\begin{array}{l}\text { Predominantly } \\
\text { rural }\end{array}$ \\
\hline Characteristic & $\begin{array}{l}41 \\
(100 \%)\end{array}$ & $25(61 \%)$ & $16(39 \%)$ \\
\hline $\begin{array}{l}\text { Age, mean years } \\
\text { (SD) }\end{array}$ & $\begin{array}{l}38.4 \\
(5.8)\end{array}$ & $39.4(5.3)$ & $36.9(6.3)$ \\
\hline \multicolumn{4}{|l|}{ Gender } \\
\hline Male & $21(51)$ & $11(44)$ & $10(63)$ \\
\hline Female & $20(49)$ & $14(56)$ & $6(38)$ \\
\hline \multicolumn{4}{|c|}{ Assigned focus group } \\
\hline Latinx & $10(24)$ & $3(12)$ & $7(44)$ \\
\hline Black & $14(34)$ & $14(56)$ & $0(0)$ \\
\hline White & $17(42)$ & $8(32)$ & $9(56)$ \\
\hline \multicolumn{4}{|c|}{ Self-reported ethnicity/race* } \\
\hline Latinx & $10(24)$ & $3(12)$ & $7(44)$ \\
\hline Black & $12(29)$ & $12(48)$ & $0(0)$ \\
\hline White & $12(29)$ & $5(20)$ & $7(44)$ \\
\hline Multiple/other & $7(17)$ & $5(20)$ & $2(13)$ \\
\hline \multicolumn{4}{|c|}{ Academic attainment } \\
\hline $\begin{array}{l}\text { Less than high } \\
\text { school }\end{array}$ & $2(5)$ & $2(8)$ & $0(0)$ \\
\hline $\begin{array}{l}\text { High school } \\
\text { graduate or GED }\end{array}$ & $8(20)$ & $4(16)$ & $4(25)$ \\
\hline Some college & $8(20)$ & $4(16)$ & $4(25)$ \\
\hline 2-year college & $10(24)$ & $5(20)$ & $5(31)$ \\
\hline 4-year college & $6(15)$ & $4(16)$ & $2(13)$ \\
\hline $\begin{array}{l}\text { Master's degree } \\
\text { or higher }\end{array}$ & $7(17)$ & $6(24)$ & $1(6)$ \\
\hline $\begin{array}{l}\text { HbAlc, mean } \\
\text { (SD) }\end{array}$ & $7.0(1.7)$ & $7.2(1.8)$ & $6.8(1.6)$ \\
\hline
\end{tabular}

* Self-reported on survey administered during focus group meeting. We allowed more options for response than is captured in the EHR-reported data that was used to assign focus groups

and collegial. Deductive analysis informed the four major themes, while the subthemes were determined inductively (Table 2).

\section{Theme 1: Sense of Preparedness for Diagnosis}

Many participants reported that they "expected" the diagnosis based on their family history, stating that they "knew the symptoms" or "always had the fear." Some participants were not surprised based on a preceding prediabetes diagnosis. Among participants who did not expect the diagnosis, most presented to their provider with symptoms that they did not attribute to diabetes or thought they were seeing their provider for "routine" bloodwork. Several participants who knew of their increased type 2 diabetes risk due to family history also reported surprise because of active efforts they had made to prevent diabetes.

\section{Theme 2: Disclosure Setting}

Some participants were told by their provider that they "can't talk on the phone" and were asked to come into the office. Several others were informed via phone. For some, the perceived casualness of telephonic disclosure did not match their perception of the seriousness of the diagnosis; as one participant stated, he would have preferred a "come-see-me" rather than a "you're a type 2 diabetic" phone call. Several participants received secure electronic messages from their provider via the health system's online patient portal. A few participants learned of their new diabetes diagnosis when they reviewed automatically released lab results via the patient portal. Individuals who first saw their results without context on the patient portal described being struck by a sense that the information was incomplete. One participant stated that she "didn't know what any of it meant."

\section{Theme 3: Perceived Provider Tone During Disclosure}

The tone of the message communicated by the disclosing clinician, as perceived by participants, fell into one of three broad and contrasting categories. Some participants felt the provider was "just real nonchalant," and that the tone of the initial conversation minimized the seriousness and significance of the diagnosis. Several participants with this perceived experience attributed the nonchalant tone of the disclosure to the pervasiveness of diabetes and their sense that having diabetes has become the "norm." In contrast, other participants perceived their provider's tone as too pessimistic and centered only on the potential negative consequences of diabetes, emphasizing the importance of getting diabetes management "all right." A third group of participants, who perceived the initial diagnosis conversation more positively, felt that the tone of the conversation was encouraging, and that their providers emphasized the available resources and manageability of type 2 diabetes, reassuring them that they would "do it [referring to diabetes management] together."

\section{Theme 4: Emotional Reaction to Disclosure}

Participants described a range of initial emotions upon receiving the diagnosis, including acceptance, denial, guilt, and fear. Participants who described more immediate acceptance of the diagnosis often cited a family history of diabetes or a sense that the diagnosis was inevitable and that they would "probably end up with it." Such discussions were more prominent in the non-White focus groups than the White focus groups. A few participants reported initial denial, either trying to rationalize the abnormal result ("I ate a lot of cake") or acting as if the diagnosis had not occurred, such as "eating all kind of stuff" they knew was not conducive to diabetes self-management. For participants who reported feeling guilty, this emotion was rooted in self-blame and the belief that the diagnosis resulted from personal missteps. As one participant put it, "I had done it to myself." Many individuals with a family history of diabetes also reported significant fear upon receiving the diagnosis, which was rooted in adverse outcomes suffered by close relatives with diabetes.

\section{DISCUSSION}

We examined the crucial moment when younger adults received their life-changing diagnosis of type 2 diabetes. We identified four major themes regarding participants' diagnosis 
Table 2 Themes, Subthemes, and Representative Quotes

\begin{tabular}{|c|c|}
\hline \multicolumn{2}{|l|}{ Preparedness for diagnosis } \\
\hline Prepared & $\begin{array}{l}\text { I would be really thirsty like my mouth was super-dry, and my mother has diabetes, so I kind of knew the symptoms... } \\
\text { and sure enough, she said I had diabetes. (P2*) } \\
\ldots \text { my dad also has type } 2 \text { diabetes...I always had the fear that I would get it...my doctor wanted to do more additional } \\
\text { blood work, and then it turned out that I did have type } 2 \text { diabetes as well. (P1) } \\
\text { I wasn't really surprised...both of my parents have it...my doctor was always really informative about how susceptible } \\
\text { I was to it... (P4) }\end{array}$ \\
\hline Not prepared & $\begin{array}{l}\text { I came in just for a yearly checkup on, you know, bloodwork for HIV and all that...two days later the doctor called and } \\
\text { said, "Mr. X, you need to come back in." I thought I had something. (P15) } \\
\text { The doctor had me do like bloodwork or whatever for nothing related to that, and all of a sudden, I got a call maybe a } \\
\text { couple weeks later. (P10) } \\
\text { The diabetes was a shock "cause I always felt like I was always doing better than my mom...(P12) } \\
\text { I was literally running away from it by exercising so much...(P16) }\end{array}$ \\
\hline \multicolumn{2}{|r|}{ 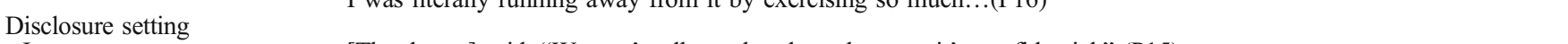 } \\
\hline & [The doctor] said, "We can’t talk on the phone because it's confidential." (P15) \\
\hline Telephone & $\begin{array}{l}\text {...we spent like } 20 \text { minutes on the phone when I was diagnosed. (P20) } \\
\text { I would have preferred a "come-see-me" phone call versus a "You're a type } 2 \text { diabetic..." (P12) } \\
\text {..did the bloodwork and the Monday after he calls me and he said, "You know I have bad news for you. You have } \\
\text { diabetes" ...I thought maybe even just calling me in and having me sit down...(P9) }\end{array}$ \\
\hline $\begin{array}{l}\text { Secure message or patient } \\
\text { portal }\end{array}$ & $\begin{array}{l}\text { I was at work one day feeling dizzy, so I left, went and saw the doctor, did bloodwork, and then I got an email. "You } \\
\text { got diabetes." (P8) } \\
\text { I actually seen my results online 'cause I have the app, and I didn't know what any of it meant. (P14) }\end{array}$ \\
\hline \multicolumn{2}{|r|}{ 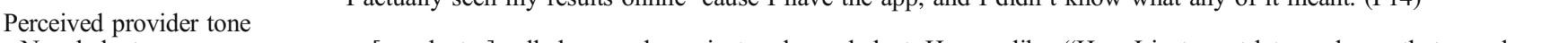 } \\
\hline Nonchalant & $\begin{array}{l}\text {... [my doctor] called me and was just real nonchalant. He was like, "Hey, I just want let you know that, you know, } \\
\text { you're diabetic." I'm like, "What do you mean I'm a diabetic?"(P19) } \\
\ldots \text {..just calling me on a Monday in the afternoon and saying, "Guess what? You have diabetes"...it's a major disease, it } \\
\text { really is, and it's not to be taken lightly, (P9) } \\
\text { P24: Well, I think it's casual because it's so common now } \\
\text { P21: ...Like it's the norm or something } \\
\text { P24: Here. Go find the pamphlet. Go sign up for the class. Take care of yourself. } \\
\text { P21: Take metformin and call me in the morning. }\end{array}$ \\
\hline Pessimistic & $\begin{array}{l}\text { They really put the fear like, "This is a chronic, progressive disease and your kidneys are going to fail and your liver's } \\
\text { going to fail...you're probably going to have a heart attack...You need to get this all right". (P7) } \\
\text {.. I'm like, "Are you sure I have diabetes?" She's like, "Yes, and this is your life plan, and you're going to die."... } \\
\text { dialysis and all this...she had me scared to death. (P6) } \\
\text { I got the phone call from my doctor, "You need to be on metformin. You need to be freaked out about this." (P23) }\end{array}$ \\
\hline Encouraging & $\begin{array}{l}\text { She gave me her time. She told me not to worry. There's lots of things that we could start.... she said, "You're not by } \\
\text { yourself...this is hard, but it's going to be easy, because we're going to do it together." (P18) } \\
\text { My doctor called me in and she talked about the test results... she was like, "You're young. You can do this. Change } \\
\text { your eating habits. Work out." (P14) }\end{array}$ \\
\hline \multicolumn{2}{|l|}{ Emotional reaction } \\
\hline & $\begin{array}{l}\text { growing up all my life...You're always being told...this aunt or grandmother's got it....in the back of my head, } \\
\text { knowing that if I don't take care of myself, I'm going to probably end up with it. (P5) } \\
\text { I kinda had it in the back of my head like, "Oh, I probably have it, too", I started crying because I was like “...I can't } \\
\text { believe that this is happening to me"...And like my biggest fear did come true. (P1) }\end{array}$ \\
\hline Denial & $\begin{array}{l}\text {..I just had a birthday. I ate a lot of cake. Everything's fine... But then he, you know, he called and then I was in } \\
\text { denial for like a whole - for a week or two. (P9) } \\
\text {...I went through that denial. I was like I don't care no more. I was eating all kind of stuff. (P13) }\end{array}$ \\
\hline Guilt & $\begin{array}{l}\text { I felt I had done it to myself...I had made decisions in the last year or so that we're not good, overeating....portion } \\
\text { control. (P9) } \\
\text { Nobody else in my family has diabetes. It's just myself, because I did it to myself. (P11) }\end{array}$ \\
\hline Fear & $\begin{array}{l}\text { Nobody else in my family has diabetes. It's just myself, because I did it to myself. (P11) } \\
\text { [My mom's] had diabetes - my entire life, and she's even went through the whole dialysis. She's had the kidney } \\
\text { transplant, everything. So, I was just like great. (P12) } \\
\ldots \text { my mom-she's had it for, I don't know, 20-something years, and she never took care of it, so she has a lot of other } \\
\text { health issues related to diabetes, and I didn't want to be in her shoes. (P3) } \\
\text {...because once I hear "diabetes"-my dad died from diabetes and I kinda got scared. (P4) }\end{array}$ \\
\hline
\end{tabular}

$* P$, participant

disclosure experiences. First, prior to receiving the diabetes diagnosis, individuals had differing levels of preparedness. Second, people received the diagnosis in a variety of settings, including in-person, over the phone, by secure message, and via the patient portal. Third, participants had contrasting perceptions of the provider's tone during the disclosure conversation, with those who felt more positively describing the tone as supportive and encouraging. Finally, strong emotional reactions were ubiquitous and included acceptance, denial, guilt, and fear.

Despite the seriousness of younger-onset type 2 diabetes, there are no standardized approaches for disclosing the diagnosis. Existing frameworks for delivering bad news outline steps providers should consider when communicating bad news and have been applied in other clinical settings. Two well-known examples are SPIKES (Set up the interview, assess patient's Perception regarding the situation, elicit Invitation from patient on how they want to receive the information, share the Knowledge, handle patient's Emotions empathetically, Summarize the conversation) and ABCDE (prepare patient in Advance, Build a therapeutic environment, Communicate the information well, Deal with the patient's reactions, and Encourage and validate patient's emotions). ${ }^{33-36}$ While there are some between-framework differences, 
common elements include (1) assessing and preparing the patient in advance of the disclosure, (2) establishing the appropriate setting for the conversation, (3) carefully communicating the information, and (4) addressing patient's emotions. Contextualizing our identified themes within these frameworks and identifying areas of commonality and difference may inform strategies to improve the disclosure of diabetes diagnoses to younger-onset individuals.

The "routes" to diagnosis described by participants mirror those previously described by Peel et al. ${ }^{18}$ Assessing individuals' pre-diagnosis perceptions may support disclosure conversations by lessening the shock for individuals who are not expecting the diagnosis (routine screening, symptoms not attributed to diabetes), and by providing the opportunity to learn about individuals' perceived diabetes risk and diabetesrelated family experiences. The surprise some participants described upon receiving the diagnosis suggests a missed opportunity to proactively counsel patients regarding diabetes and their personal risk, especially since diabetes screening is not routine for individuals under age 45 years. Knowing which individuals have been expecting or dreading this diagnosis due to their family history can help providers shape their approach to this difficult conversation. HIV testing serves as a relevant clinical exemplar for pre-diagnosis preparation. Clinical protocols stress the importance of "pre-HIV testing counseling," during which the provider assesses an individual's perceived HIV risk, describes the testing process, discusses interpretation of results, outlines next steps and available resources if the result is positive, and provides an opportunity for patients to ask questions. ${ }^{20}$

The frameworks for breaking bad news highlight the importance of the setting, with most implementation examples assuming an in-person setting. However, this expectation may be outdated, or impractical, as primary care increasingly occurs through telemedicine and electronic messages. These options provide greater convenience for many patients and may improve care access for vulnerable patient populations. ${ }^{37-39}$ Still, the disclosure of a diabetes diagnosis via telephone or secure message may be at odds with some individuals' expectations. Establishing new best practices for diabetes diagnosis disclosure in the current care environment, particularly in light of shifts to virtual care during the COVID-19 pandemic, requires an understanding of patients' preferences (i.e., how they want to learn about test results), plans for addressing potential information gaps (i.e., if results are automatically released, how should they be presented?), and an evaluation of how the disclosure setting affects diabetes-related outcomes (e.g., care engagement, diabetes distress).

Participants' differing perceptions of the provider's tone during the disclosure may signal the need for pre-diagnosis assessment and tailored communication strategies. The provider's nonchalant tone described by some participants may reflect the ubiquity of type 2 diabetes in primary care. Individuals with type 2 diabetes are frequent visitors to primary care providers, with almost half having six or more office visits each year (compared with $13 \%$ of the general population). ${ }^{1,40}$ This frequent exposure to patients with type 2 diabetes may result in a "normalization" of the condition for clinicians that is at odds with the singularity of the experience for a newly diagnosed younger individual. On the other end of the spectrum, some participants felt the tone of the provider's disclosure was overly focused on the potential negative consequences of the diagnosis. It seems likely that these providers hoped to leverage fear of adverse outcomes to motivate positive behavior change. Yet, the psychology literature suggests that fear-based appeals may not be well-suited to diabetesrelated behavior changes. First, fear is a better motivator of single changes (e.g., flu vaccination) than persisting behavior modifications like those required for type 2 diabetes selfmanagement. ${ }^{41}$ Second, the relationship between fear and motivation is not linear and, past a certain threshold, fearbased appeals may become discouraging. ${ }^{42}$ Many newly diagnosed individuals are already quite afraid of disease-related complications, with patients actually overestimating their risk for these outcomes. ${ }^{43,44}$ Finally, for fear to shift behaviors, individuals need to believe they can make the changes needed to avoid the feared outcome ${ }^{45}$. The self-efficacy of newly diagnosed individuals may differ greatly based on expectations regarding the diagnosis, prior success navigating difficult behavior changes, and family experiences with type 2 diabetes, all of which likely shape individuals' responses to fear-based appeals. ${ }^{46,47}$ For example, for an individual actively working to avoid type 2 diabetes, the diagnosis may be especially damaging to their self-efficacy and limit the effectiveness of fear as a motivator.

The range of emotional reactions to receiving a diabetes diagnosis may reflect differences in baseline expectations and experiences with type 2 diabetes. The negative emotions described by participants were often rooted in a sense of failure to prevent diabetes in spite of the known risk or active preventative efforts, and, for many, were influenced by traumatic family experiences with diabetes. These initial emotions may be a first signal of increased diabetes distress, which is known to be higher among individuals with younger-onset type 2 diabetes. ${ }^{10,11}$ Diabetes distress, specifically the sense that this diagnosis was unavoidable or that future complications are inevitable, may be particularly pronounced among race/ethnic minority populations where type 2 diabetes and resulting complications are more prevalent. ${ }^{48}$ Given the links between greater diabetes distress and worse self-care and glycemic control, efforts to acknowledge and validate initial emotions and to address signs of diabetes distress may help individuals cope with the diagnosis and support self-management efforts. ${ }^{10,49}$

Our results must be interpreted within the context of the study design. The research was conducted in a relatively small sample of individuals who were all members of the same healthcare delivery system, limiting generalizability 
to other settings. KPNC is a leader in the use of virtual care, potentially making the reported variations in disclosure settings unique. However, with the rapid growth of virtual care, the relevance of our findings will likely increase. The study design does not support between-group comparisons based on race/ethnicity or geography. For example, the greater mention of type 2 diabetes family history among non-White participants may reflect particular group member characteristics (that are not related to race/ethnicity) and group dynamics (i.e., openness) rather than actual race/ ethnicity-based differences in the role of family history. Focus group participants may be more engaged than typical patients or may have had more negative or positive care experiences that motivated participation. Participants' responses were susceptible to recall bias, as well as social desirability bias (influence of group, research team members are KPNC employees). Finally, participants were all proficient in English, and the findings may not reflect the experiences of non-English proficient individuals.

Individuals diagnosed with diabetes at a younger age will live longer with this condition and are more likely to incur debilitating disease-related complications compared to those diagnosed later in life. Taken together, our findings highlight opportunities to improve the diagnosis experience for younger-onset individuals by (1) making patients aware of their diabetes risk and assessing their perceptions regarding the diagnosis prior to testing, (2) establishing the patientpreferred setting for receiving the results, as well as best practices if a virtual visit is the preferred, or only, option, (3) communicating the information in a supportive manner, and (4) directly addressing patients' emotions. Although the diagnosis disclosure is only one of many steps in the diabetes care process, communication approaches that better meet patients' expectations and emotional needs may help high-risk, younger-onset individuals establish a trajectory towards improved health from the start.

Supplementary Information The online version contains supplementary material available at https://doi.org/10.1007/s11606-02006481-y

Acknowledgments: We acknowledge Amy J. Markowitz, JD, for her editorial assistance with this manuscript. We also want to acknowledge Dr. Eileen Kim and Dr. Brian Dolnick, two KPNC physicians, for their support and help in operationalizing the focus group meetings. Finally, we want to acknowledge Dr. Michael T. Nguyen for providing feedback on the manuscript.

Corresponding Author: Anjali Gopalan, MD, MS; Kaiser Permanente Northern California Division of Research, Oakland, CA, USA (e-mail: Anjali.Gopalan@kp.org).

Authors' Contributions All the listed authors have met the requirements for authorship. A.G. oversaw the study design, data analysis, and results interpretation, and wrote the manuscript. M.A.B. contributed to the study design, took field notes during the focus group meetings, analyzed the data, and participated in the writing/ reviewing of the manuscript. A.A. contributed to the study design, particularly the focus group guide, facilitated the focus groups, supported the data analysis, and participated in the writing/ reviewing of the manuscript. P.M. identified eligible individuals from the EHR data, assisted with participant recruitment infrastructure, and contributed to the writing/reviewing of the manuscript. I.F. contributed clinical expertise to initial proposal development and study design and reviewed the manuscript. R.W.G. contributed to study design and reviewed/edited the manuscript. A.G. is the guarantor of this study and manuscript.

Funding The study was funded by an award from the Kaiser Permanente Northern California Division of Research Health Policy and Disparities Research Program. A.G. was also supported by a National Institute of Diabetes and Digestive and Kidney Diseases (NIDDK) grant, K23DK116968. RWG had support from an NIDDK grant, K24DK109114. The funders had no role in the design and conduct of the study, the completed analysis, the interpretation of the data, or the content and preparation of the manuscript.

Data Availability The data generated and/or analyzed during the current study are not publicly available due to institutional policies but are available from the corresponding author on reasonable request and with the appropriate IRB approvals.

Corresponding Author: Anjali Gopalan, MD, MS; Kaiser Permanente Northern California Division of Research, Oakland, CA, USA (e-mail: Anjali.Gopalan@kp.org).

\section{Compliance with Ethical Standards:}

Conflict of Interest: The authors declare that they do not have a conflict of interest.

\section{REFERENCES}

1. Centers for Disease Control and Prevention. National Diabetes Statistics Report, 2020. Atlanta, GA: Centers for Disease Control and Prevention, U.S. Dept. of Health and Human Services; 2020.

2. Hillier TA, Pedula KL. Complications in young adults with early-onset type 2 diabetes: losing the relative protection of youth. Diabetes Care. 2003;26(11):2999-3005

3. Chan JC, Lau ES, Luk AO, et al. Premature mortality and comorbidities in young-onset diabetes: a 7-year prospective analysis. Am $\mathrm{J}$ Med. 2014;127(7):616-624.

4. Song SH, Gray TA. Early-onset type 2 diabetes: high risk for premature diabetic retinopathy. Diabetes Res Clin Pract. 2011;94(2):207-211.

5. Bo A, Thomsen RW, Nielsen JS, et al. Early-onset type 2 diabetes: Age gradient in clinical and behavioural risk factors in 5115 persons with newly diagnosed type 2 diabetes-Results from the DD2 study. Diabetes Metab Res Rev. 2018;34(3). https://doi.org/10.1002/dmrr.2968.

6. Benhalima K, Wilmot E, Khunti K, Gray LJ, Lawrence I, Davies M. Type 2 diabetes in younger adults: clinical characteristics, diabetesrelated complications and management of risk factors. Prim Care Diabetes. 2011;5(1):57-62

7. Hillier TA, Pedula KL. Characteristics of an adult population with newly diagnosed type 2 diabetes: the relation of obesity and age of onset. Diabetes Care. 2001;24(9):1522-1527.

8. Berkowitz SA, Meigs JB, Wexler DJ. Age at type 2 diabetes onset and glycaemic control: results from the National Health and Nutrition Examination Survey (NHANES) 2005-2010. Diabetologia. 2013;56(12):2593-2600.

9. Gopalan A, Mishra P, Alexeeff SE, et al. Initial glycemic control and care among younger adults diagnosed with type 2 diabetes. Diabetes Care. 2020;43(5):975-981. https://doi.org/10.2337/dc19-1380.

10. Hessler DM, Fisher L, Mullan JT, Glasgow RE, Masharani U. Patient age: a neglected factor when considering disease management in adults with type 2 diabetes. Patient Educ Couns. 2011;85(2):154-159.

11. Browne JL, Nefs G, Pouwer F, Speight J. Depression, anxiety and self- 
care behaviours of young adults with Type 2 diabetes: results from the International Diabetes Management and Impact for Long-term Empowerment and Success (MILES) Study. Diabet Med. 2015;32(1):133-140.

12. Holman RR, Paul SK, Bethel MA, Matthews DR, Neil HA. 10-year follow-up of intensive glucose control in type 2 diabetes. N Engl J Med. 2008;359(15):1577-1589.

13. Laiteerapong $\mathbf{N}$, Ham SA, Gao $\mathbf{Y}$, et al. The Legacy Effect in Type 2 Diabetes: Impact of Early Glycemic Control on Future Complications (The Diabetes \& Aging Study). Diabetes Care. 2019;42(3):416-426.

14. Strelitz J, Ahern AL, Long GH, et al. Moderate weight change following diabetes diagnosis and 10 year incidence of cardiovascular disease and mortality. Diabetologia. 2019;62(8):1391-1402.

15. Polonsky WH, Capehorn M, Belton A, et al. Physician-patient communication at diagnosis of type 2 diabetes and its links to patient outcomes: New results from the global IntroDia(R) study. Diabetes Res Clin Pract. 2017; 127:265-274.

16. Lawson VL, Bundy C, Belcher J, Harvey JN. Changes in Coping Behavior and the Relationship to Personality, Health Threat Communication and Illness Perceptions from the Diagnosis of Diabetes: A 2-year Prospective Longitudinal Study. Health Psychol Res. 2013;1(2):e20.

17. Parry O, Peel E, Douglas M, Lawton J. Patients in waiting: a qualitative study of type 2 diabetes patients' perceptions of diagnosis. Fam Pract. 2004;21(2):131-136.

18. Peel E, Parry O, Douglas M, Lawton J. Diagnosis of type 2 diabetes: a qualitative analysis of patients' emotional reactions and views about information provision. Patient Educ Couns. 2004;53(3):269-275.

19. Capehorn M, Polonsky WH, Edelman S, et al. Challenges faced by physicians when discussing the Type 2 diabetes diagnosis with patients: insights from a cross-national study (IntroDia((R)) ). Diabet Med. 2017;34(8):1100-1107.

20. Branson BM, Handsfield HH, Lampe MA, et al. Revised recommendations for HIV testing of adults, adolescents, and pregnant women in health-care settings. MMWR Recomm Rep. 2006;55(RR-14):1-17; quiz CE11-14.

21. Mack JW, Fasciano KM, Block SD. Communication About Prognosis With Adolescent and Young Adult Patients With Cancer: Information Needs, Prognostic Awareness, and Outcomes of Disclosure. J Clin Oncol. 2018;36(18): 1861-1867

22. Coenen M, Stamm TA, Stucki G, Cieza A. Individual interviews and focus groups in patients with rheumatoid arthritis: a comparison of two qualitative methods. Qual Life Res. 2012;21(2):359-370.

23. Guest G, Namey E, Taylor J, Eley N, McKenna K. Comparing focus groups and individual interviews: findings from a randomized study. Int $J$ Soc Res Methodol. 2017;20(6):693-708.

24. Guest G, Namey E, McKenna K. How Many Focus Groups Are Enough? Building an Evidence Base for Nonprobability Sample Sizes. Field Methods. 2017;29(1):3-22

25. Schroeder EB, Donahoo WT, Goodrich GK, Raebel MA. Validation of an algorithm for identifying type 1 diabetes in adults based on electronic health record data. Pharmacoepidemiol Drug Saf. 2018;27(10):10531059. https://doi.org/10.1002/pds.4377.

26. Klompas M, Eggleston E, McVetta J, Lazarus R, Li L, Platt R. Automated detection and classification of type 1 versus type 2 diabetes using electronic health record data. Diabetes Care. 2013;36(4):914-921.

27. Leask J, Hawe $\mathbf{P}$, Chapman $\mathbf{S}$. Focus group composition: a comparison between natural and constructed groups. Aust $\mathrm{N} \mathrm{Z} \mathrm{J} \mathrm{Public} \mathrm{Health.}$ 2001;25(2):152-154

28. Greenwood N, Ellmers T, Holley J. The influence of ethnic group composition on focus group discussions. BMC Med Res Methodol. 2014; 14:107

29. Lieblich A, Tuval-Mashiach R, Zilber T. Narrative research : reading, analysis and interpretation. Thousand Oaks, Calif: Sage Publications; 1998.
30. Clandinin DJ, Connelly FM. Narrative inquiry : experience and story in qualitative research. 1st San Francisco: Jossey-Bass Publishers; 2000.

31. Patton MQ. Enhancing the quality and credibility of qualitative analysis. Health Serv Res. 1999;34(5 Pt 2):1189-1208.

32. Braun V, Clarke V. Using thematic analysis in psychology. Qual Res Psychol. 2006;3(2):77-101.

33. Baile WF, Buckman R, Lenzi R, Glober G, Beale EA, Kudelka AP. SPIKES-A six-step protocol for delivering bad news: application to the patient with cancer. Oncologist. 2000;5(4):302-311.

34. VandeKieft GK. Breaking bad news. Am Fam Physician. 2001;64(12):1975-1978.

35. von Blanckenburg $\mathbf{P}$, Hofmann M, Rief W, Seifart U, Seifart C. Assessing patients preferences for breaking Bad News according to the SPIKES-Protocol: the MABBAN scale. Patient Educ Couns. 2020;103(8):1623-1629. https://doi.org/10.1016/j.pec.2020.02.036.

36. Rabow MW, McPhee SJ. Beyond breaking bad news: how to help patients who suffer. West J Med. 1999;171(4):260-263.

37. Kvedar J, Coye MJ, Everett W. Connected health: a review of technologies and strategies to improve patient care with telemedicine and telehealth. Health Aff (Millwood). 2014;33(2): 194-199.

38. Ray KN, Chari AV, Engberg J, Bertolet M, Mehrotra A. Disparities in Time Spent Seeking Medical Care in the United States. JAMA Intern Med. 2015;175(12):1983-1986.

39. Reed ME, Huang J, Parikh R, et al. Patient-Provider Video Telemedicine Integrated With Clinical Care: Patient Experiences. Ann Intern Med. 2019;171(3):222-224.

40. McEwan LN, Herman WH. Health care utilization and costs of diabetes. In: Diabetes in America. Vol 17. Bethesda, MD: National Institutes of Health; 2017.

41. Tannenbaum MB, Hepler J, Zimmerman RS, et al. Appealing to fear: A meta-analysis of fear appeal effectiveness and theories. Psychol Bull. 2015;141(6):1178-1204.

42. Higbee KL. Fifteen years of fear arousal: research on threat appeals: 1953-1968. Psychol Bull. 1969;72(6):426-444.

43. Hendricks LE, Hendricks RT. Greatest fears of type 1 and type 2 patients about having diabetes: implications for diabetes educators. Diabetes Educ. 1998;24(2):168-173.

44. Kuniss N, Freyer M, Muller N, Kielstein V, Muller UA. Expectations and fear of diabetes-related long-term complications in people with type 2 diabetes at primary care level. Acta Diabetol. 2019;56(1):33-38.

45. Kok G, Peters G-JY, Kessels LTE, ten Hoor GA, Ruiter RAC. Ignoring theory and misinterpreting evidence: the false belief in fear appeals. Health Psychol Rev. 2018;12(2):111-125.

46. Ruiter RA, Kessels LT, Peters GJ, Kok G. Sixty years of fear appeal research: current state of the evidence. Int J Psychol. 2014;49(2):63-70.

47. Manyiwa S, Brennan R. Fear appeals in anti-smoking advertising: How important is self-efficacy? J Mark Manag. 2012;28(11-12):1419-1437.

48. CMS OMH and NORC. Racial and Ethnic Disparities in Diabetes Prevalence, Self-Management, and Health Outcomes among Medicare Beneficiaries. . CMS OMH Data Highlight No. 6 Web site. https://www. cms.gov/About-CMS/Agency-Information/OMH/research-and-data/information-products/data-highlights/disparities-in-diabetes-prevalence. Published 2017. Accessed September 22, 2020.

49. Pandit AU, Bailey SC, Curtis LM, et al. Disease-related distress, selfcare and clinical outcomes among low-income patients with diabetes. J Epidemiol Community Health. 2014;68(6):557-564.

Publisher's Note Springer Nature remains neutral with regard to jurisdictional claims in published maps and institutional affiliations. 